Article

\title{
A Phenology-Based Classification of Time-Series MODIS Data for Rice Crop Monitoring in Mekong Delta, Vietnam
}

Nguyen-Thanh Son ${ }^{1 \%}$, Chi-Farn Chen ${ }^{1}$, Cheng-Ru Chen ${ }^{2}$, Huynh-Ngoc Duc ${ }^{3}$ and Ly-Yu Chang ${ }^{1}$

1 Center for Space and Remote Sensing Research, National Central University, Taoyuan 32001, Taiwan; E-Mails: cfchen@csrsr.ncu.edu.tw (C.-F.C.); lychang@csrsr.ncu.edu.tw (L.-Y.C.)

2 Department of Civil Engineering, National Central University, Taoyuan 32001, Taiwan; E-Mail: ccruncu@gmail.com

3 Faculty of Agriculture and Natural Resources, An Giang University, 18 Ung Van Khiem St., Long Xuyen City, Vietnam; E-Mail: hnduc@agu.edu.vn

* Author to whom correspondence should be addressed; E-Mail: ntson@csrsr.ncu.edu.tw; Tel.: +886-09-3301-2400.

Received: 27 September 2013; in revised form: 13 December 2013 / Accepted: 14 December 2013 / Published: 20 December 2013

Abstract: Rice crop monitoring is an important activity for crop management. This study aimed to develop a phenology-based classification approach for the assessment of rice cropping systems in Mekong Delta, Vietnam, using Moderate Resolution Imaging Spectroradiometer (MODIS) data. The data were processed from December 2000, to December 2012, using empirical mode decomposition (EMD) in three main steps: (1) data pre-processing to construct the smooth MODIS enhanced vegetation index (EVI) time-series data; (2) rice crop classification; and (3) accuracy assessment. The comparisons between the classification maps and the ground reference data indicated overall accuracies and Kappa coefficients, respectively, of $81.4 \%$ and 0.75 for $2002,80.6 \%$ and 0.74 for 2006 and $85.5 \%$ and 0.81 for 2012 . The results by comparisons between MODIS-derived rice area and rice area statistics were slightly overestimated, with a relative error in area (REA) from $0.9-15.9 \%$. There was, however, a close correlation between the two datasets $\left(\mathrm{R}^{2} \geq 0.89\right)$. From 2001 to 2012 , the areas of triple-cropped rice increased approximately $31.6 \%$, while those of the single-cropped rain-fed rice, double-cropped irrigated rice and double-cropped rain-fed rice decreased roughly $-5.0 \%,-19.2 \%$ and $-7.4 \%$, respectively. This study demonstrates the validity of such an approach for rice-crop monitoring with MODIS data and could be transferable to other regions. 
Keywords: MODIS; EMD; phenology-based classification; rice cropping systems

\section{Introduction}

Rice is an important food crop for half of the world's population [1]. Rice agriculture is a key socioeconomic driving force of Asian developing countries [2,3], providing livelihoods and employment for a majority of rural populations. The impacts of climate change through global warming have substantially modified temperature and precipitation patterns [4], leading to environmental and food security issues, such as land degradation and decreased crop production [5-11]. The phenomenon is especially evident for low-lying coastal deltas [12] where rice is commonly cultivated. In addition, the rapid growth of the world's population at a rate of $1.1 \%$ per annum, expected to reach nine billion by the middle of this century [13], is also a critical issue triggering the world's increasing demands for food and other agricultural products [14]. Thus, meeting the food needs of the world's growing population while safeguarding the environment is a matter of urgency that calls for an agenda of effective rice agriculture monitoring.

Vietnam's economy is dependent on rice agriculture, with more than $50 \%$ of this country's population engaged in rice agriculture for their livelihood and subsistence. Rice production contributes approximately $21 \%$ of Vietnam's gross domestic product [15], and this country annually produces approximately 39.9 million tons of rice [15], designating it the second largest rice supplier in the world after Thailand. The Mekong Delta, known as the "rice bowl" of Vietnam, contributes $85 \%$ of the country's total rice exports [16]. The region is documented to be one of the most low-lying coastal deltas; however, it is extremely vulnerable to the impacts of climate change [12], including floods, droughts, salinization and rice diseases, which can undermine rice-crop production. Monitoring rice-growing areas to assist agronomic planners with yearly rice production estimates is therefore critical to developing successful strategies for food security and rice grain exports for the country.

The Moderate Resolution Imaging Spectroradiometer (MODIS) has demonstrated great potential for regional rice-crop monitoring [17-21], because of the advantages, such as a wide coverage, high spectral and temporal resolutions and free access to data acquisition. However, MODIS data are often contaminated by cloud cover that potentially lowers the accuracy of classification results; therefore, studies using MODIS time series for rice-crop surveys often apply noise-filtering techniques to the data to minimize impacts on the mapping results prior to analysis. Some of the most commonly used techniques for noise filtering of time-series satellite data include the Fourier transform [22-24], the wavelet transform [25,26], the Gaussian model, the logistic model, the Whittaker filter [24] and empirical mode decomposition (EMD) [19,25], which was used in this study [27] to filter noise from the MODIS enhanced vegetation index (EVI) time-series data. The advantage of the EMD filtering method is that it does not require the assuming of a stationary or non-stationary signal prior to the signal decomposition; rather, the signal can be adaptively decomposed into a number of intrinsic mode functions (IMFs) and a residue. From these IMFs and the residue, the low-pass, high-pass and band-pass filters can be designed to filter out noises from the signal [28].

A number of techniques have been used for crop extraction and land-cover classification, including the threshold-based method [17,29,30], and supervised classifiers, such as the maximum likelihood 
algorithm [31], support vector machines [32] and artificial neural networks [33]. One of the disadvantages of the threshold-based method was selecting appropriate thresholds that were the most reliable cut-offs to perform the classification. Likewise, the supervised classification algorithms required training samples to perform the classification. One challenge of using these supervised classifiers for long-term classification of rice cropping systems in the study area is selecting appropriate training datasets for different land-cover classes, due to changes in the land cover over time. Different training datasets applied to different year rice-crop system classification data could lead to inconsistent mapping results. In this study, we were most concerned with identifying an automatic approach for long-term delineation of rice cropping systems in the region. Because satellite vegetation indices, such as EVI, are correlated with green biomass [34] and different correlation levels between vegetation indices and biomass were obtained for different phenological stages [35-40], we used the phenological information of rice crops, such as sowing, heading and harvesting periods, to develop a classification approach to long-term rice monitoring in the region over space and time.

The main objective of this study was to develop a phenology-based mapping approach for a decadal assessment of rice cropping systems in the Mekong Delta, South Vietnam, using the MODIS EVI time-series data for a 12-year period (from 2001 to 2012) using EMD. The results could be used by agronomic planners to annually estimate rice-growing areas and rice-crop production.

\section{Study Area and Rice Crop Phenology}

The Mekong Delta study area, located in South Vietnam between $8.5-11.0 \mathrm{E}$ and $104.5-106.6 \mathrm{~N}$ (Figure 1), comprises 13 provinces and covers approximately $40,000 \mathrm{~km}^{2}$. We noted that Can Tho and Hau Giang were separated from the former Can Tho province in the beginning of 2004. The region has a tropical monsoonal climate with a mean temperature of $27.5{ }^{\circ} \mathrm{C}$ and precipitation of $1,442 \mathrm{~mm}$. The year has two distinct seasons. The dry season lasts from December to April, while the wet season from May to Nov provides approximately $80 \%$ of the total annual precipitation. A complex network of natural streams and manmade canals in the study area include more than $10,000 \mathrm{~km}$ of irrigation canals constructed to deliver irrigation water throughout the region for agricultural production and transportation. The terrain of this region is mostly agriculturally productive plateaus. Roughly $71.6 \%$ of the total area is arable land, $90 \%$ of which is agricultural land allocated for rice production [15].

Irrigated rice is commonly practiced in the region and is considered the most important income source for a majority of rural households. Five cropping seasons per year are observed in the region, including the rainy season (July-August to December-January), the winter-spring season (November-December to February-March), the spring-summer season (March-April to May-June), the summer-autumn season (April-May to July-August) and the autumn-winter season (July-September to October-December). These seasons form four main rice-cropping systems: single-cropped rain-fed rice (rainy season), double-cropped irrigated rice (spring-summer and summer-autumn seasons), double-cropped rain-fed rice (summer-autumn and autumn-winter seasons) and triple-cropped irrigated rice. Depending on the area, an extra crop of triple-cropped irrigated rice, either spring-summer or summer-autumn, was added into the double-cropped irrigated rice system. The rain-fed rice cropping system using long-duration varieties (160-180 days) was invariably practiced in areas that were subject to soil and water constraints, while the irrigated rice cropping systems using 
short-duration varieties (90-100 days) were practiced in areas where irrigation conditions were favorable.

Figure 1. The 2002 land-cover map of the study area showing different rice cropping systems and the locations of sampling sites used for the accuracy assessment of the classification results.

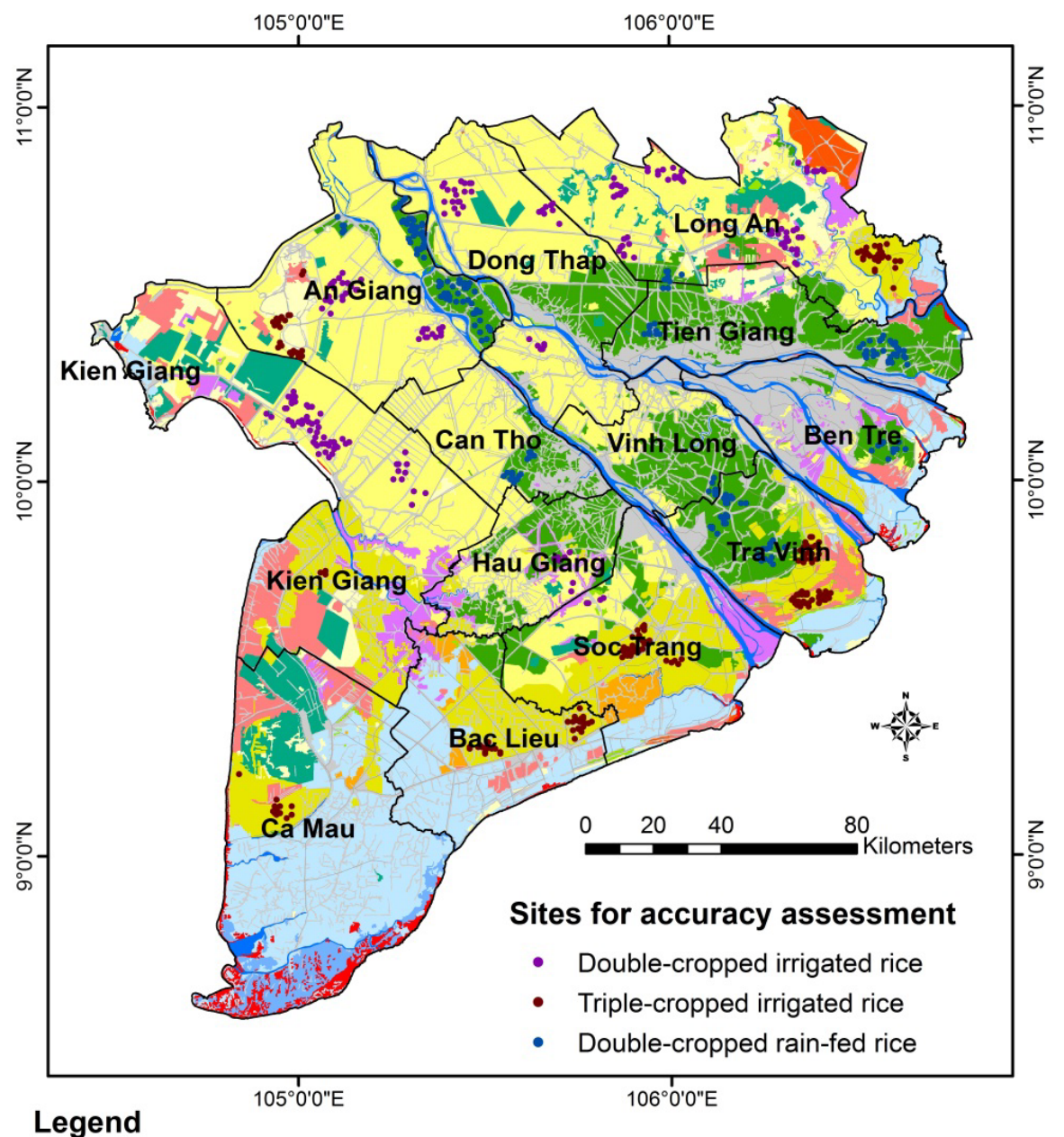

\begin{tabular}{|l|l|}
\hline Single-cropped rain-fed rice & Settled areas/orchards/coconut \\
\hline Single-cropped rain-fed rice/upland crops & Melaleuca/eucalyptus forests \\
\hline Single-cropped rain-fed rice/shrimp culture & Mangrove forest/shrimp farm \\
\hline Double-cropped irrigated rice & Mangrove forests \\
\hline Double-cropped rain-fed rice & Shrimp farm \\
\hline Triple-cropped irrigated rice & Others/unused land \\
\hline Pineapple/sugarcane & River network \\
\hline Vegetables/upland crops & Road network \\
\hline
\end{tabular}

Rice crop phenology in the region involves three main periods: (1) The sowing period begins when rice seeds are sown directly into flooded soils $(2-5 \mathrm{~cm}$ water). The EVI responses from rice fields during this period are thus very low. (2) The growing period follows the sowing period and encompasses the vegetative, reproductive and ripening stages. The vegetative stage is characterized by a rapid increase in plant height, the number of tillers and leaf development to reach the heading phase, and therefore, EVI intensifies rapidly during this period. After heading, the plant changes from 
the vegetative stage to the reproductive stage, when the plants cease to increase in height and biomass and the leaves begin to wither and die. During this period, the EVI intensity also starts leveling off. From sowing to harvesting, the growing period lasts approximately 60 days, about 30 of which are from heading to harvesting dates. (3) The fallow period follows harvesting, when the rice fields are mostly bare or flooded during the rainy season (July-December), and the EVI responses from rice fields are very low.

\section{Data Collection}

\subsection{MODIS Data}

The MODIS/Terra Surface Reflectance eight-day L3 Global 500 m SIN Grid v005 (MOD09A1) acquired from the National Aeronautics and Space Administration (NASA) for rice-cropping seasons during the period December, 2000, to December, 2012, were used in this study. The dataset consists of seven spectral bands with a spatial resolution of $500 \mathrm{~m}$. Each pixel of this data product contains the best possible L2G observation during an eight-day period, selected on the basis of high observation coverage, low viewing angle, the absence of clouds and aerosol loading [41]. The data have been geometrically and radiometrically corrected for all spectral bands and, therefore, are appropriate for scientific publications $[41,42]$.

\subsection{Ground Reference Data and Rice Area Statistics}

Ancillary maps, including the 2002 and 2006 Mekong land-cover maps (scale: 1/125,000) were collected from the Sub-National Institute of Agricultural Planning and Projection, Vietnam for crosschecking and preparation of the ground reference data used for accuracy assessment of the classification results. Because land-cover maps for the entire study period were unavailable, a reference map was generated by conducting field surveys in 2012. Accuracy assessment of the 2002, 2006 and 2012 classification results relied on the map, which was created based on the analysis of existing land-cover maps, Google Earth imagery and information recorded from the 2012 field surveys. We digitized sampling sites of homogenous rice fields for each class that had not changed between 2002, 2006 and 2012 (Figure 1). The ground reference was converted to a raster map (500 m resolution). Rice area statistics at the provincial level were also collected from the Vietnam General Statistics Office and were used to verify the consistency between the classification results and the government rice area statistics.

\section{Methodology}

Four main steps were comprised of the data processing (Figure 2): (1) constructing the smooth MODIS EVI time-series data for the period 2000 to 2012; (2) non-rice area masking; (3) rice crop classification; and (4) accuracy assessment. The analysis of changes in rice cultivation was also examined. 
Figure 2. Flowchart of the methodology showing steps of data processing used in this study. EVI, enhanced vegetation index. MODIS, Moderate Resolution Imaging Spectroradiometer.

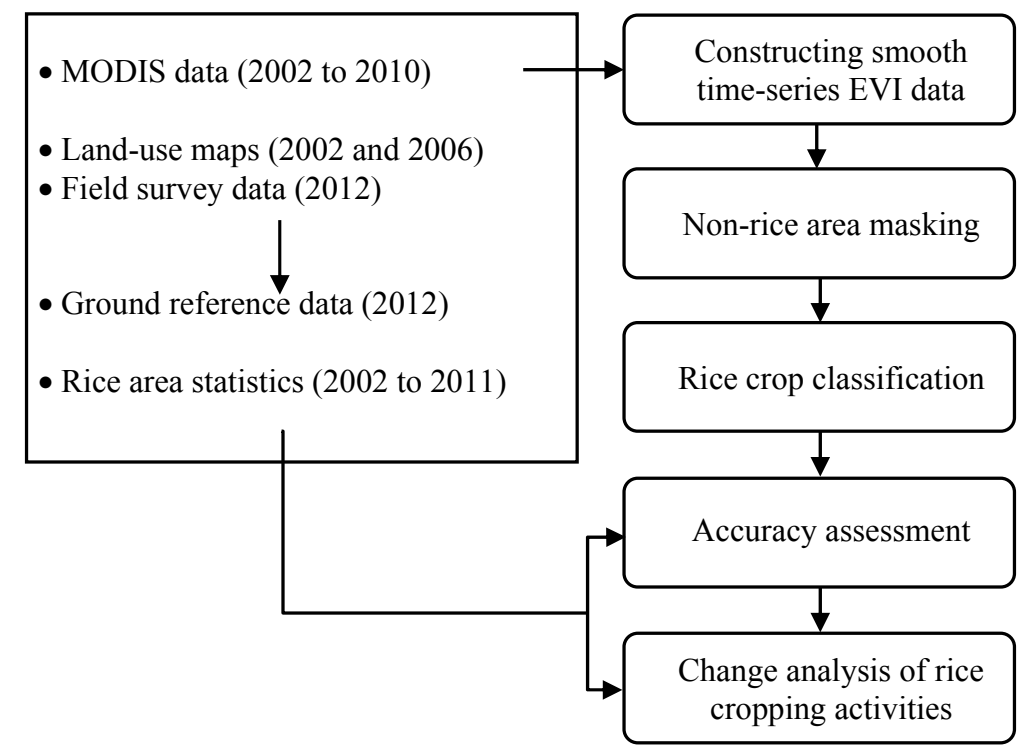

\subsection{Constructing Smooth Time-Series EVI Data}

The MODIS data were formatted using a Sinusoidal projection, but were reprojected to the Universal Transverse Mercator coordinate system (Zone $48 \mathrm{~N}$ ), mosaicked and subset over the study area. The EVI was used in this study to investigate temporal responses of rice fields, calculated using the following formula:

$$
\mathrm{EVI}=2.5 \times \frac{\rho_{\text {nir }}-\rho_{\text {red }}}{\rho_{\text {nir }}+6 \times \rho_{\text {red }}-7.5 \times \rho_{\text {blue }}+1}
$$

where $\rho_{\text {red }}(620-670 \mathrm{~nm}), \rho_{\text {nir }}(841-876 \mathrm{~nm}), \rho_{\text {blue }}(459-479 \mathrm{~nm})$ are MODIS bands 1,2 and 3. To create EVI time-series data for the period December 2000, to December 2012, we first computed EVI for every 8-day MODIS image. These EVI images for this 12-year period were then stacked into an 8-day composite scene (556 bands).

Noises in EVI time-series data were caused by cloud cover. Noisy data were denoised in a two-step procedure: (1) pixels covered by clouds were first removed if the values of the blue band were greater than 0.2 [43], and the missing values were replaced with new values from the time-series profile using linear interpolation [26,44]; and (2) the EMD method [27], which has been widely used to filter noise from vegetation indices time-series data $[19,45]$, was then applied to smooth the EVI time series. This method decomposes the EVI time series into a set of IMFs and a residue. An IMF was extracted by averaging the extrema points in the EVI time-series profile using the cubic spline interpolation method through iterations until it satisfied two stoppage conditions: (1) the number of extrema and the number of zero crossings must be equal or differ by one; and (2) the mean value of the envelope defined by the local maxima and the envelope defined by the local minima [46] must equal zero at all points [27]. 


\subsection{Non-Rice Area Masking}

In this study, the IMF3 derived from EMD processing of EVI time-series data was used to mask out non-rice cropped areas (e.g., orchards/fruit trees, forests, built-up areas and water bodies/shrimp farms), and the smooth EVI time-series data derived from a low-pass filter by adding the last six IMFs $\left(c_{3} \sim c_{8}\right)$ and the residue $(r)$ were used for rice crop classification. This IMF3 was used for the masking process, because the patterns of non-rice cropped areas revealed a relatively stable fluctuation of EVI intensity throughout the year compared to those of rice cropping systems (Figure 3). Thus, the intensity of IMF3 of these non-rice cropped patterns was also lower than those of rice-cropping patterns. This characteristic enabled us to mask out non-rice cropped areas using IMF3, where its mean values calculated for the entire period of rice cropping seasons in each year were lower than 0.05 . This threshold was the most reliable cut-off for separating rice and non-rice cropped areas, which was determined based on the results achieved by comparing the masking results with the 2002 and 2006 land-cover maps using different thresholds. We noted that the pattern of single-cropped rain-fed rice in the study area had a relatively stable fluctuation of EVI intensity in the time-series profile, and its EVI intensity was relatively low throughout the year (Figure 3a).

Figure 3. The IMF3 (intrinsic mode function) obtained from the empirical mode decomposition (EMD) sifting for different signals of land-use types in the study area: (a) single-cropped rain-fed rice, (b) double-cropped irrigated rice, (c) double-cropped rain-fed rice, (d) triple-cropped irrigated rice, (e) orchards/fruit trees, (f) forests, (g) built-up areas and (h) water bodies/shrimp farms.
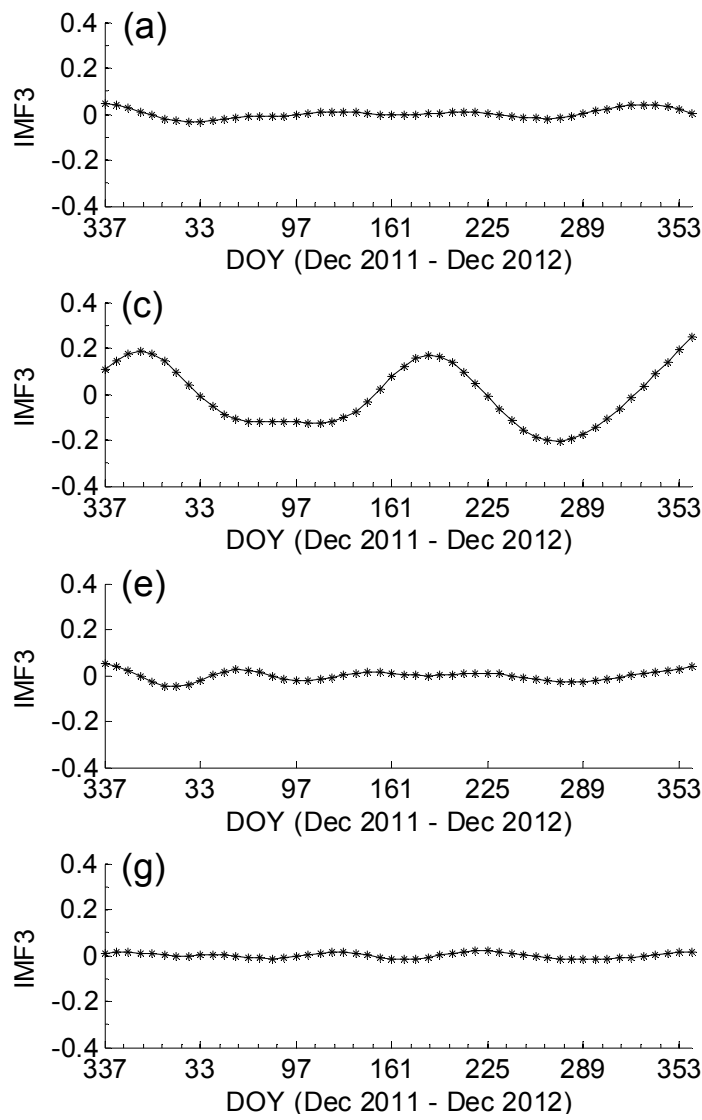
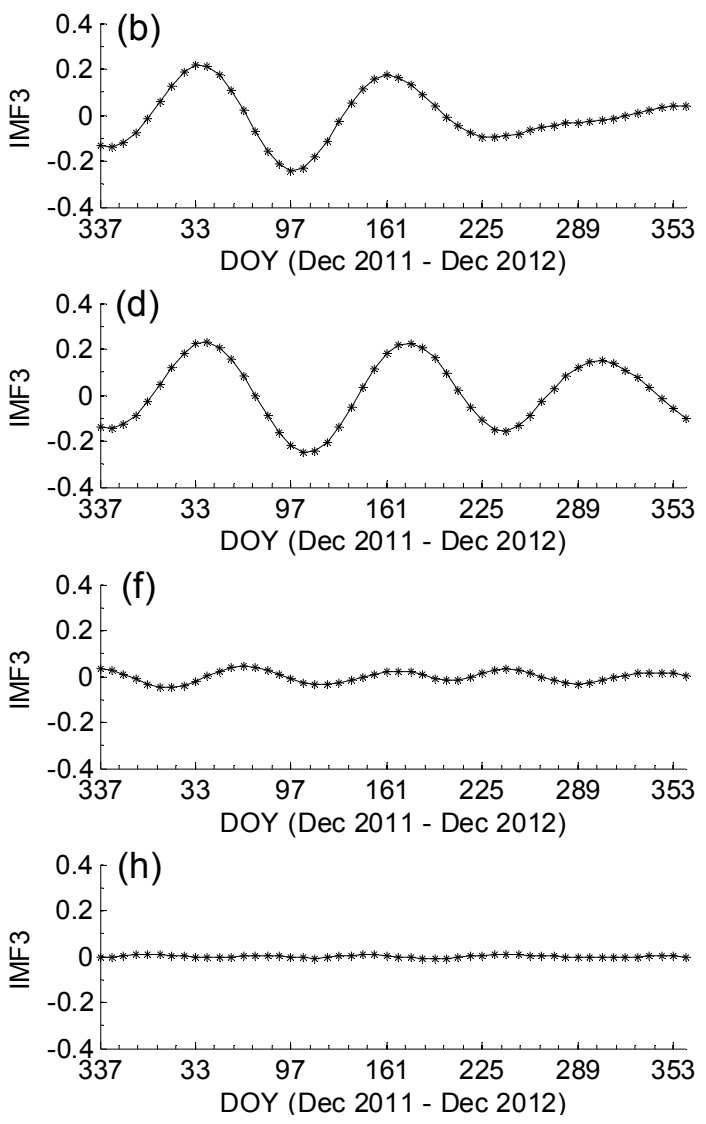
The IMF3 produced from the single-cropped rice pattern was especially confused with those from non-rice cropped areas, such as orchards/fruit trees and forests. An additional masking condition was thus used to separate the single-cropped rain-fed rice from similar patterns using the smooth EVI during the heading and ripening periods of this rice cropping system (October-December). Because the single-cropped rain-fed rice was practiced during the flood season and the rice fields during this period were still flooded, the EVI intensity of the greenness of this cropping pattern generally increased from greater than 0.1 on reaching a maximum value (heading date) of lower than 0.35 and began to level off by the end of December. The EVI intensity of the single-cropped rain-fed rice during this period was much lower than that of forests and orchards/fruit trees, which had a high and relatively stable EVI intensity throughout the year. Thus, a threshold was set to eliminate patterns of forests and orchards/fruit trees from that of single-cropped rain-fed rice if the EVI greater than 0.2 during this entire period.

\subsection{Rice Crop Classification}

A phenology-based approach was used to classify four types of rice cropping systems in the region: single-cropped rain-fed rice, double-cropped irrigated rice, double-cropped rain-fed rice and triple-cropped irrigated rice. The local maxima algorithm [46] was first applied to identify heading dates (peaks) of rice crops as the maximum values in the time EVI profile. An EVI threshold of 0.35 was then set based on the analysis of rice crop phenology to eliminate unrealistic peaks that were equal to or lower than 0.35 . Because a rice-cropping system consists of crop(s), a rice cycle should fall within a specific period of a cropping season, which was determined by checking the estimated rice cycle with the rice-cropping calendar (Figure 4). Specifically, the rainy season crop occurred between July-August to December. The cycle of the winter-spring crop should occur between December to February-March, while those of the spring-summer, summer-autumn and autumn-winter crops should fall between March-April to May-June, April-May to July-August and July-September to October-December, respectively. The interval between two heading dates should be longer than 80 days, considering a rice cycle of irrigated rice cropping systems in the region from 90-100 days.

Ultimately, the rice cropping systems (i.e., single-cropped rain-fed rice, double-cropped irrigated rice, double-cropped rain-fed rice and triple-cropped irrigated rice) were classified for each year's data from 2001 to 2012 using the number of heading dates per year and the rice-cropping calendar for the region. Therefore, if a pattern had a peak greater than 0.35 between July-August to December, it was classified as single-cropped rain-fed rice (Figure 4a). If a pattern had two peaks greater than 0.35 and the first and second peaks, respectively, occurred between December to February-March and April-May to July-August, it was classified as double-cropped irrigated rice (Figure 4b). If a pattern had two peaks greater than 0.35 and the first and second peaks, respectively, occurred between April-May to July-August and July-September to October-December, it was classified as double-cropped rain-fed rice (Figure 4c). If patterns had three peaks greater than 0.35 and either the second peak or third peak, respectively, occurred March-April to May-June and July-September to October-December, it was classified as triple-cropped irrigated rice (Figure 4c,d). 
Figure 4. Smooth EVI profiles (December, 2011, to December, 2012) show phenological information of crop phenology used for classification of rice cropping systems in the study area: (a) single-cropped rain-fed rice, (b) double-cropped irrigated rice, (c) double-cropped rain-fed rice (d) and (e) triple-cropped irrigated rice.
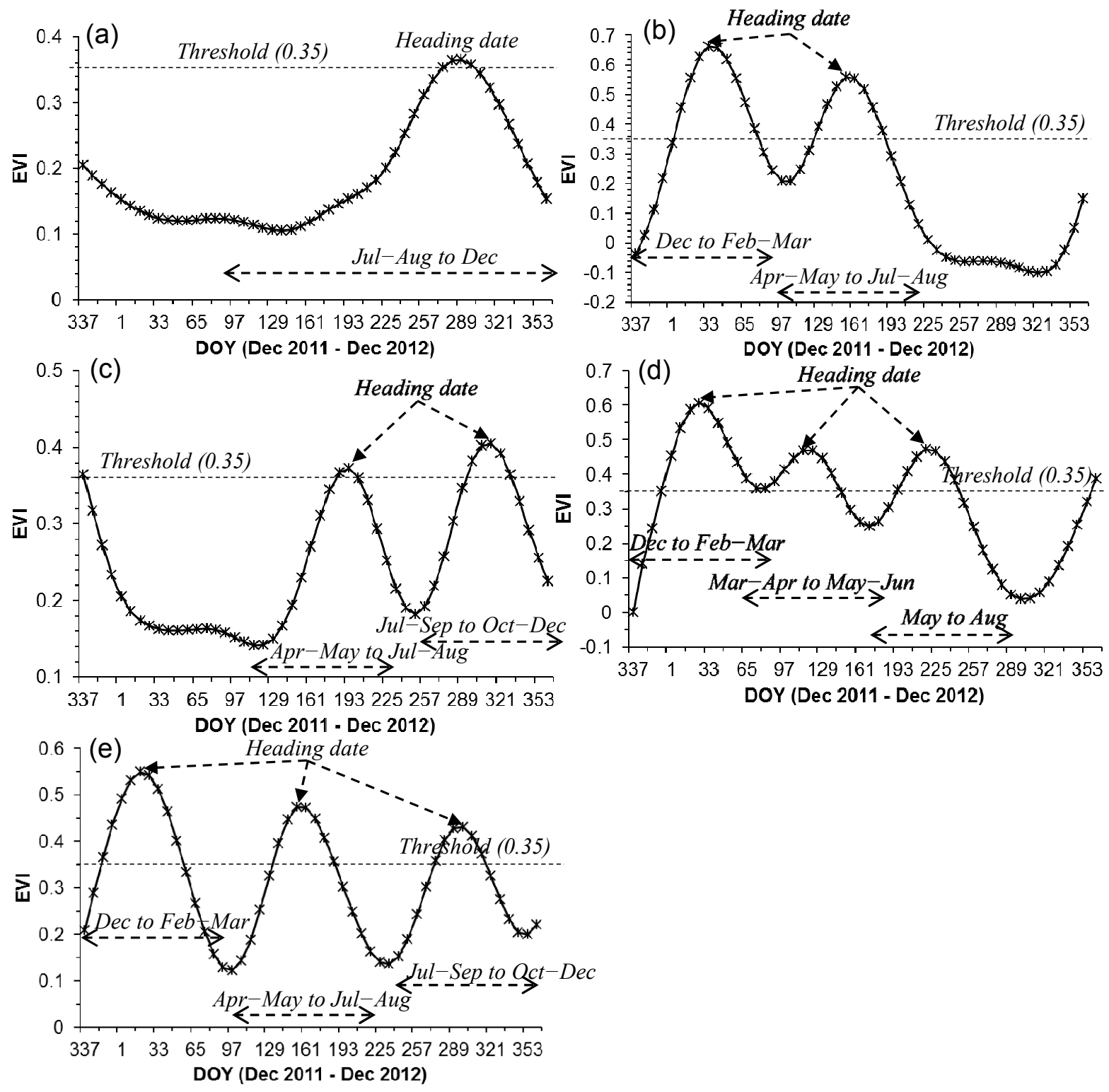

\subsection{Accuracy Assessment}

The accuracy of classification maps was validated using the ground reference data (Figure 1) created after the field surveys conducted in 2012. For each rice class, 200 pixels were randomly extracted. The confusion matrix using the overall and Kappa coefficient was used to assess the accuracy of classification results and the robustness of the classification approach. The government's rice area statistics were also used to evaluate the consistency of the classification results for each year's data using a simple regression analysis. 


\section{Results and Discussion}

\subsection{Long-Term Analysis of EVI Time Series}

The EMD sifting process was applied for every pixel of the composite EVI image (556 bands). The sifting results for a rice signal (Figure 5) showed the seasonal variations of IMF components and a residue during this period (December, 2000, to December, 2012), including the raw EVI signal, high to low frequency components $\left(c_{1}, c_{2}, \ldots c_{8}\right)$ and a residue $(r)$ (Figure 5 from top to bottom). The first two IMFs contained considerable noise in the time-series profile, due to high frequency components caused by cloud cover, but this was easily separated from the EVI time-series profile. The third IMF characterized the temporal responses of the EVI intensity from the rice fields, showing the seasonal variations of rice cropping systems throughout the year. The other IMFs $\left(c_{3} \sim c_{8}\right)$ showed the lower frequency components in the EVI time-series profile, indicating longer periodic variations of rice crops, and the residue represented the overall trend for the entire time-series profile of EVI. The low-pass filter was formed by adding the last six IMFs $\left(c_{3}\right.$ to $\left.c_{8}\right)$ and a residue $(r)$. This processing scheme allowed us to construct the smooth time-series EVI data, clearly indicating that the filtered time-series profile preserved the EVI intensity when noise was eliminated (Figure 6). The smooth time-series EVI data characterizing the temporal characteristics of rice-cropping patterns throughout the year could be used for the analysis of rice crop phenology.

Figure 5. EMD sifting results of a rice EVI signal shows the temporal variations of IMFs $\left(c_{1} \sim c_{8}\right)$ and the residue $(r)$ during December, 2000, to December, 2012.

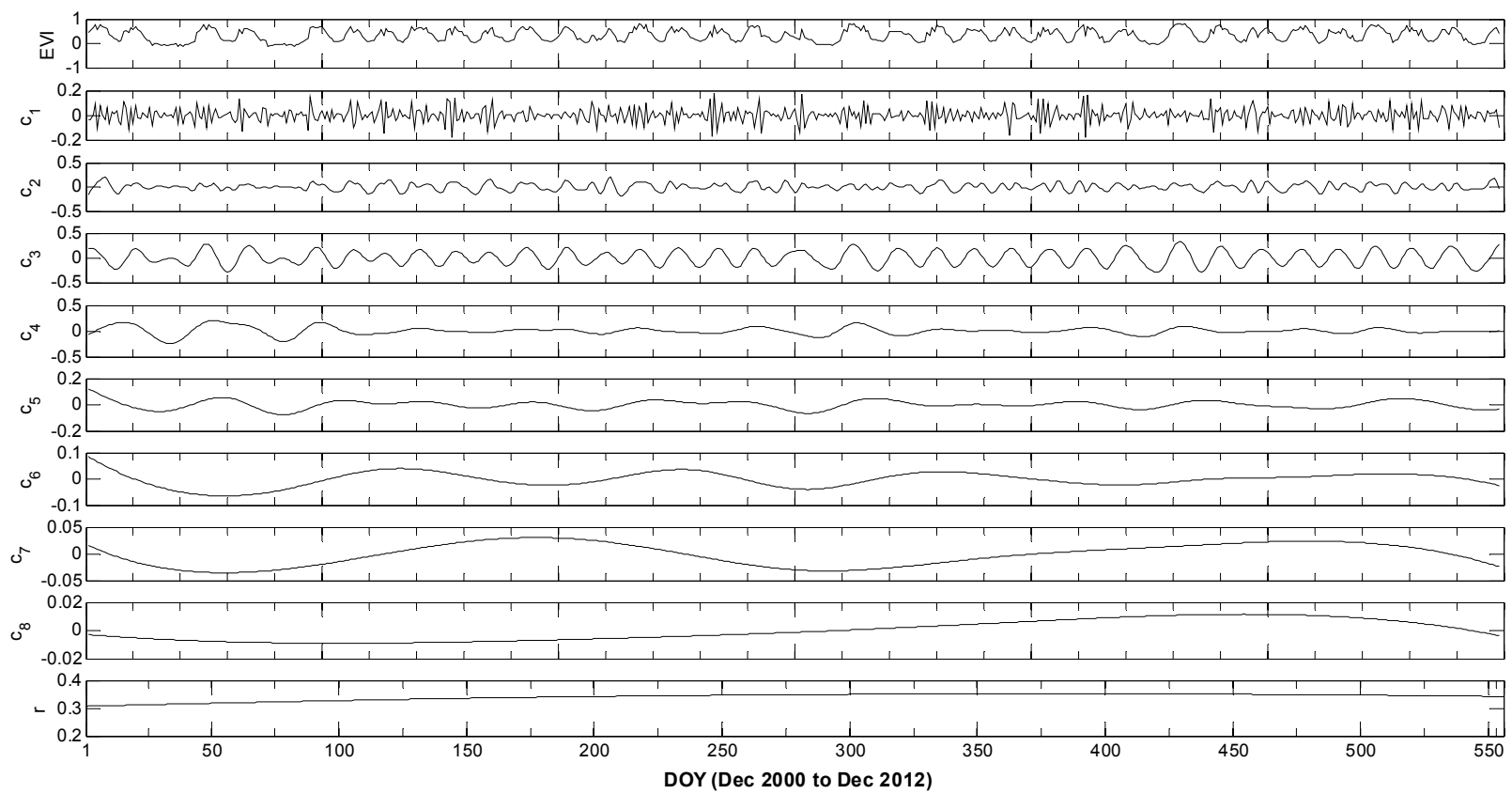


Figure 6. The raw EVI signal profile (dashed line) and the smooth profile (solid line) derived from the EMD-based low-pass filter by adding IMFs $\left(c_{3} \sim c_{8}\right)$ and the residue $(r)$ for rice-cropping seasons from December, 2000, to December, 2012.

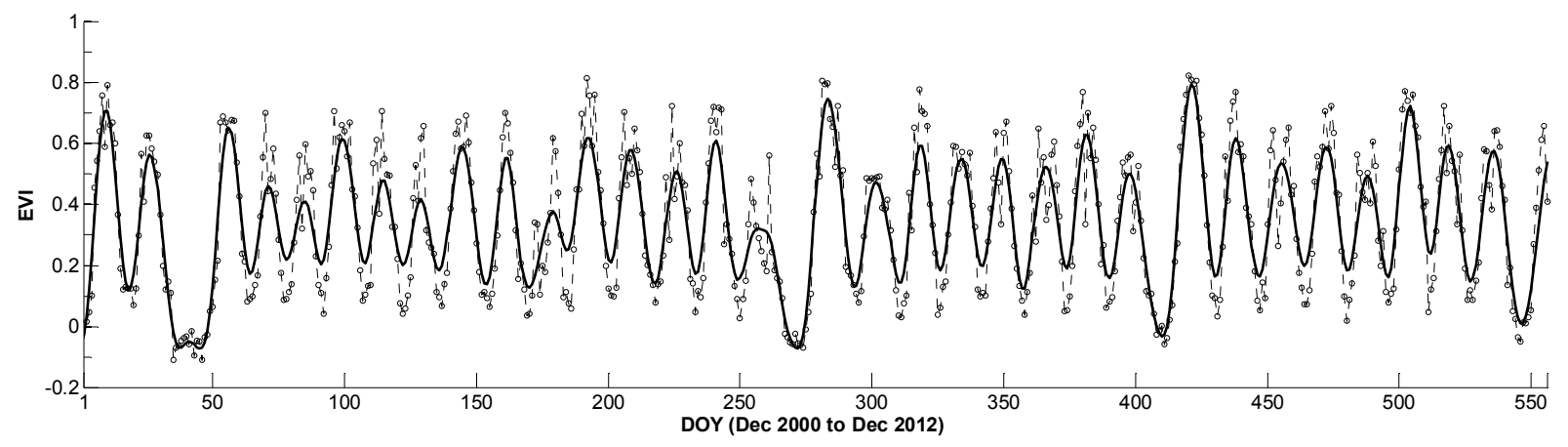

\subsection{Accuracies of the Classification Results}

The classification maps produced from the 2002, 2006 and 2012 data were compared with the ground reference data and indicated close agreement between the two datasets. The overall accuracies and Kappa coefficients were, respectively, $81.4 \%$ and 0.75 for $2002,80.6 \%$ and 0.74 for 2006 and $85.5 \%$ and 0.81 for 2012 (Table 1). The lower accuracy level was observed for the single-cropped rain-fed rice, because this rice class occupied a small area and was spatially scattered along coastal areas and, thus, was easily omitted or spectrally confused with other rice classes, especially double-cropped rain-fed rice, during the classification. In general, several error sources exaggerated the classification results. For example, the ground reference data were prepared by digitizing homogenous sites of rice fields based on the analysis of existing 2002 and 2006 land-cover maps, high-resolution Google Earth imagery and the 2012 field-survey data, while the classification maps were produced from MODIS data. The comparison between these two datasets, which were derived from different data sources, could also contribute to the increase of classification errors due to a resolution bias. Moreover, because the size of a MODIS pixel was 25 ha compared to the smaller average size of rice fields in the study area (1-2 ha), the effects of mixed-pixel problems could also cause an increase in mapping errors.

Table 1. Results of the classification accuracy assessment.

\begin{tabular}{lccccc}
\hline \multirow{2}{*}{ Ground Reference Data } & \multicolumn{4}{c}{ Classification Results (2002, 2006, and 2012) } \\
\cline { 2 - 4 } & $\begin{array}{l}\text { Single-Cropped } \\
\text { Rain-Fed Rice }\end{array}$ & $\begin{array}{c}\text { Double-Cropped } \\
\text { Irrigated Rice }\end{array}$ & $\begin{array}{c}\text { Double-Cropped } \\
\text { Rain-Fed Rice }\end{array}$ & $\begin{array}{c}\text { Triple-Cropped } \\
\text { Irrigated Rice }\end{array}$ & Total \\
\hline Single-cropped rain-fed rice & 104 & 0 & 85 & 11 & 200 \\
Double-cropped irrigated rice & 2 & 164 & 19 & 15 & 200 \\
Double-cropped rain-fed rice & 1 & 0 & 192 & 7 & 200 \\
Triple-cropped irrigated rice & 0 & 5 & 4 & 191 & 200 \\
Total & 107 & 169 & 300 & 224 & 800 \\
Producer accuracy (\%) & 52.0 & 82.0 & 96.0 & 95.5 & \\
User accuracy (\%) & 97.2 & 97.0 & 64.0 & 85.3 & \\
Overall accuracy (\%) & 81.4 & & & & \\
Kappa coefficient & 0.75 & & & & \\
\hline
\end{tabular}


Table 1. Cont.

\begin{tabular}{|c|c|c|c|c|c|}
\hline \multirow[b]{2}{*}{ Ground Reference Data } & \multicolumn{4}{|c|}{ Classification Results (2002, 2006, and 2012) } & \multirow[b]{2}{*}{ Total } \\
\hline & $\begin{array}{c}\text { Single-Cropped } \\
\text { Rain-Fed Rice }\end{array}$ & $\begin{array}{c}\text { Double-Cropped } \\
\text { Irrigated Rice }\end{array}$ & $\begin{array}{c}\text { Double-Cropped } \\
\text { Rain-Fed Rice }\end{array}$ & $\begin{array}{c}\text { Triple-Cropped } \\
\text { Irrigated Rice }\end{array}$ & \\
\hline \multicolumn{6}{|l|}{2006} \\
\hline Single-cropped rain-fed rice & 139 & 0 & 58 & 3 & 200 \\
\hline Double-cropped irrigated rice & 0 & 167 & 17 & 16 & 200 \\
\hline Double-cropped rain-fed rice & 7 & 15 & 171 & 7 & 200 \\
\hline Triple-cropped irrigated rice & 0 & 15 & 17 & 168 & 200 \\
\hline Total & 146 & 197 & 263 & 194 & 800 \\
\hline Producer accuracy (\%) & 69.5 & 83.5 & 85.5 & 84.0 & \\
\hline User accuracy (\%) & 95.2 & 84.8 & 65.0 & 86.6 & \\
\hline Overall accuracy (\%) & 80.6 & & & & \\
\hline Kappa coefficient & 0.74 & & & & \\
\hline \multicolumn{6}{|l|}{2012} \\
\hline Single-cropped rain-fed rice & 161 & 12 & 27 & 0 & 200 \\
\hline Double-cropped irrigated rice & 0 & 167 & 12 & 21 & 200 \\
\hline Double-cropped rain-fed rice & 6 & 8 & 163 & 23 & 200 \\
\hline Triple-cropped irrigated rice & 0 & 3 & 4 & 193 & 200 \\
\hline Total & 167 & 190 & 206 & 237 & 800 \\
\hline Producer accuracy (\%) & 80.5 & 83.5 & 81.5 & 96.5 & \\
\hline User accuracy (\%) & 96.4 & 87.9 & 79.1 & 81.4 & \\
\hline Overall accuracy (\%) & 85.5 & & & & \\
\hline Kappa coefficient & 0.81 & & & & \\
\hline
\end{tabular}

The relationship between the MODIS-derived rice areas and those from the government's rice area statistics at the provincial level for each year was examined. The results showed that the two datasets were strongly correlated, reaffirming the consistency with the results achieved from the accuracy classification assessment using the error matrix. The correlation coefficient $\left(\mathrm{R}^{2}\right)$ used to measure the adequacy of the regression model (Figure 7) indicated that the models could explain more than $80 \%$ of the variability in the data. In general, the classification results were slightly overestimated for all cases. The relative error in area (REA) between the MODIS-derived rice areas and the government's rice area statistics ranged from $0.9-15.9 \%$ (Table 2 ). This overestimation error was mainly attributed to the discrepancy between the two datasets; the government rice statistics were estimated as the total sown areas in which multiple rice crops were double- or triple-counted, while the MODIS-rice areas were calculated by taking the pixel counts multiplied by the double- or triple-cropped counts. The errors were exaggerated because the double- and triple-cropped rice systems were commonly practiced throughout the region. 
Figure 7. Results of regression analysis between MODIS-derived rice area and rice area statistics at the provincial level for the entire region: (a) 2001, (b) 2002 (c) 2003, (d) 2004, (e) 2005, (f) 2006, (g) 2007, (h) 2008, (i) 2009, (j) 2010, (k) 2011 and (l) 2012.
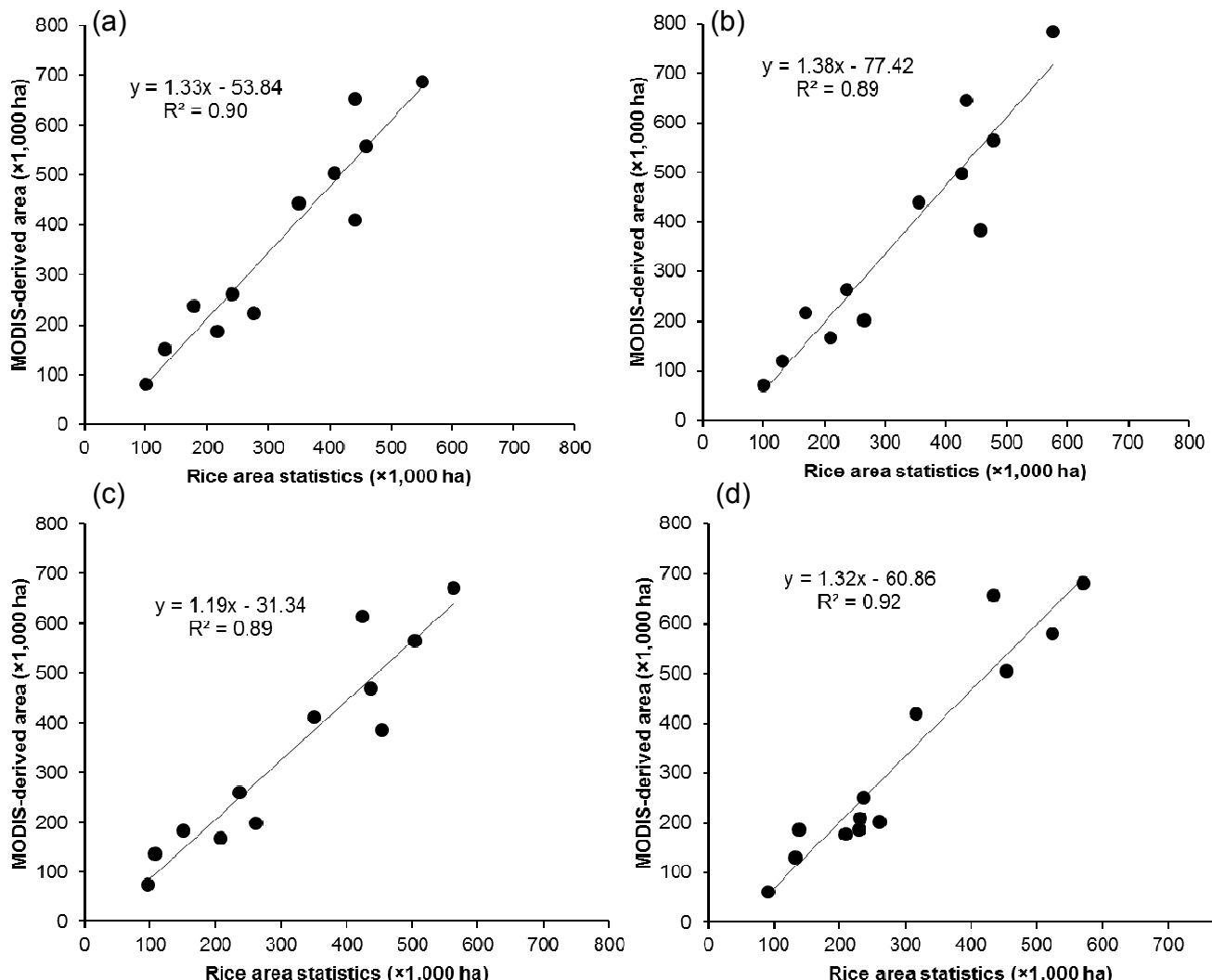

(d)

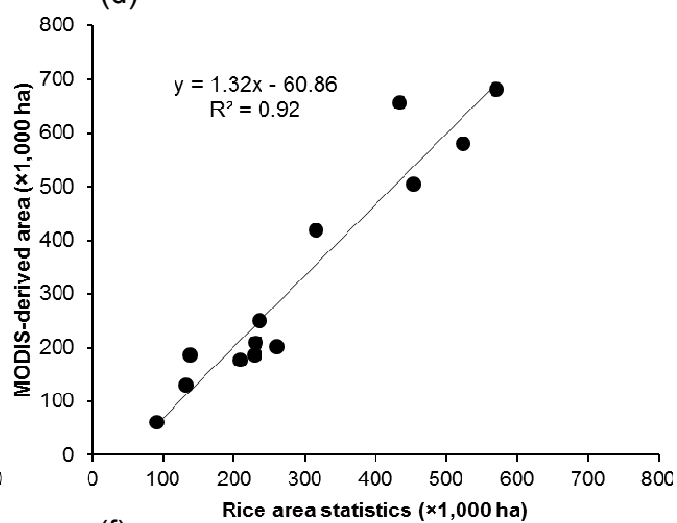

(e)

(f)
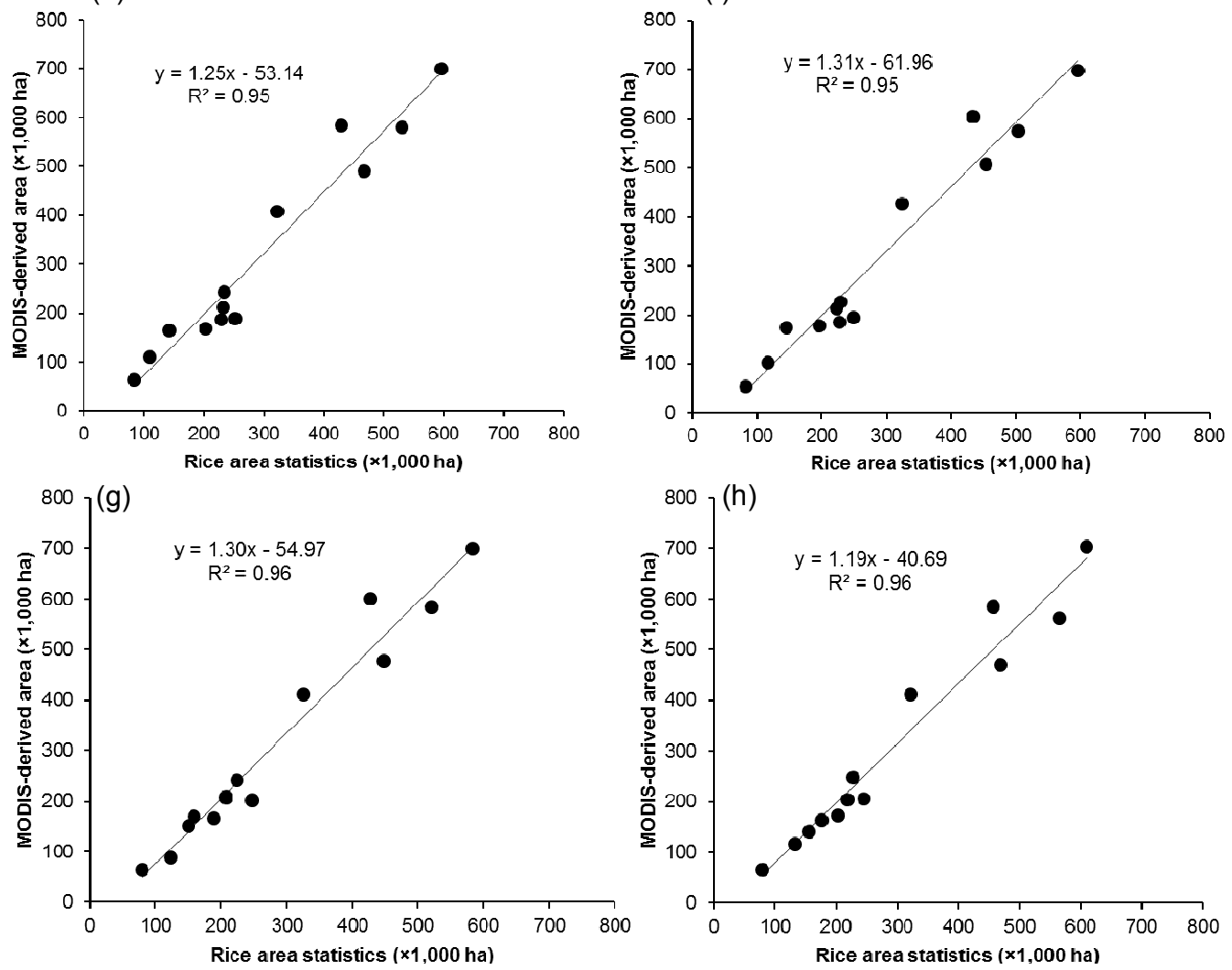
Figure 7. Cont.
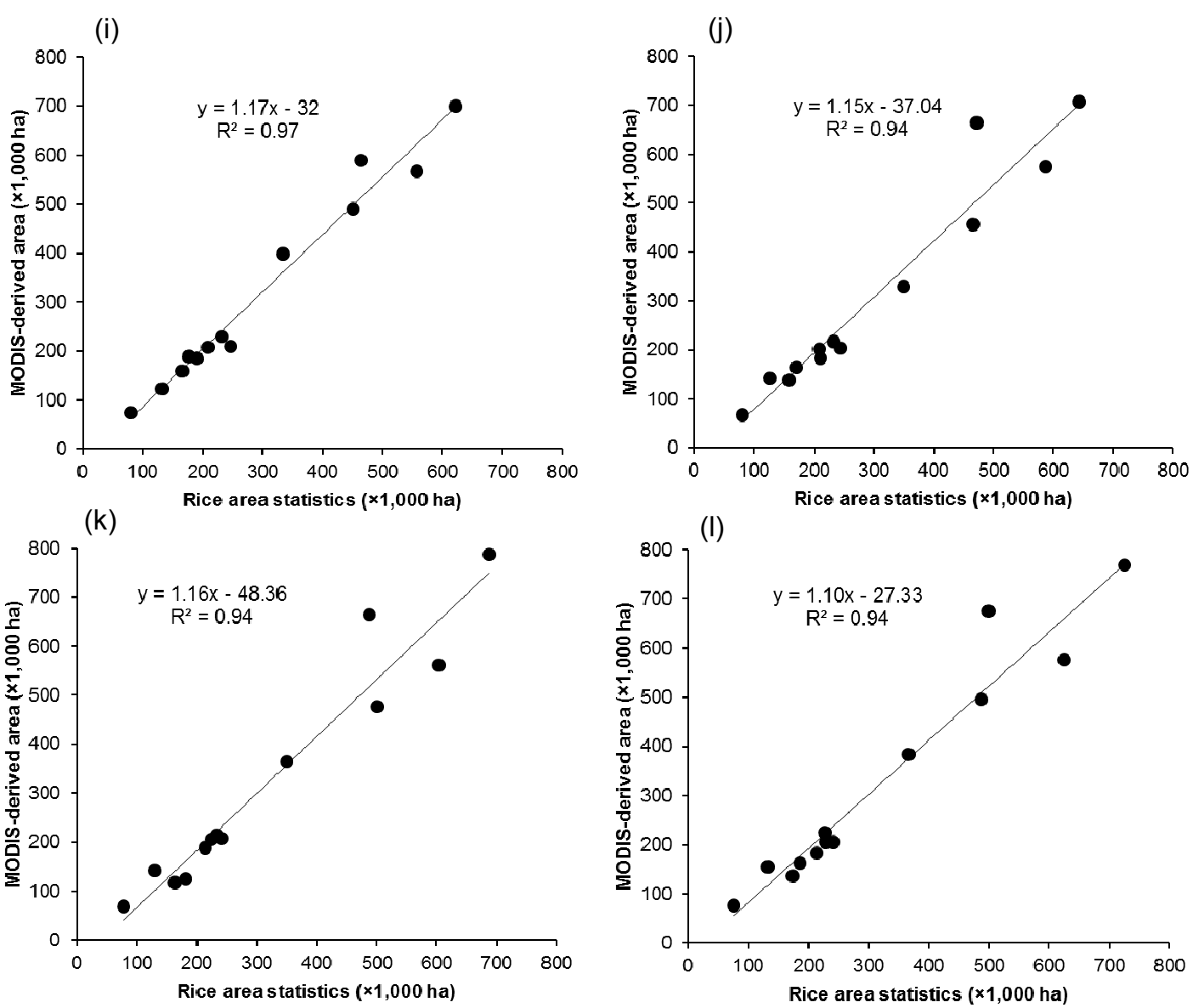

Table 2. The relative error in area (REA) between the MODIS-derived rice area and the rice area statistics, $\mathrm{REA}=(\mathrm{MOD}-\mathrm{RAS}) / \mathrm{RAS} \times 100$, where $\mathrm{RAS}=$ rice area statistics, MOD $=$ MODIS-derived rice area.

\begin{tabular}{cccc}
\hline Year & RAS $\left(\mathbf{k m}^{\mathbf{2}}\right)$ & MOD $\left(\mathbf{k m}^{\mathbf{2}}\right)$ & REA (\%) \\
\hline 2001 & $3,792.0$ & $4,393.4$ & 15.9 \\
2002 & $3,834.8$ & $4,356.1$ & 13.6 \\
2003 & $3,787.3$ & $4,136.0$ & 9.2 \\
2004 & $3,815.7$ & $4,246.2$ & 11.3 \\
2005 & $3,826.3$ & $4,095.6$ & 7.0 \\
2006 & $3,773.9$ & $4,138.2$ & 9.7 \\
2007 & $3,683.1$ & $4,060.2$ & 10.2 \\
2008 & $3,858.9$ & $4,047.7$ & 4.9 \\
2009 & $3,863.9$ & $4,121.2$ & 6.7 \\
2010 & $3,945.9$ & $4,051.4$ & 2.7 \\
2011 & $4,089.3$ & $4,126.3$ & 0.9 \\
2012 & $4,181.3$ & $4,248.5$ & 1.6 \\
\hline
\end{tabular}




\subsection{Distribution of Rice Cropping Systems and Changes in Rice Cropping Activities}

A decadal survey of the spatiotemporal evolution of rice cropping activities from 2001 to 2012 indicated that the double-cropped irrigated rice was concentrated in the upper part of the study area (Figure 8). The triple-cropped irrigated rice was particularly allocated along the central part of the region between the two large rivers (Mekong and Bassac rivers), due to the availability of water for crop irrigation around the year. The double-cropped rain-fed rice was distributed along the coastal zones, where water was limited during the dry season for rice crop irrigation. The single-cropped rain-fed rice invariably practiced during the rainy season was especially scattered along coastal areas, where soils were the major constraint for irrigated rice production.

Figure 8. Spatial distributions of rice cropping systems in the study area: (a) 2001, (b) 2002, (c) 2003, (d) 2004, (e) 2005, (f) 2006, (g) 2007, (h) 2008, (i) 2009, (j) 2010, (k) 2011 and (l) 2012 .
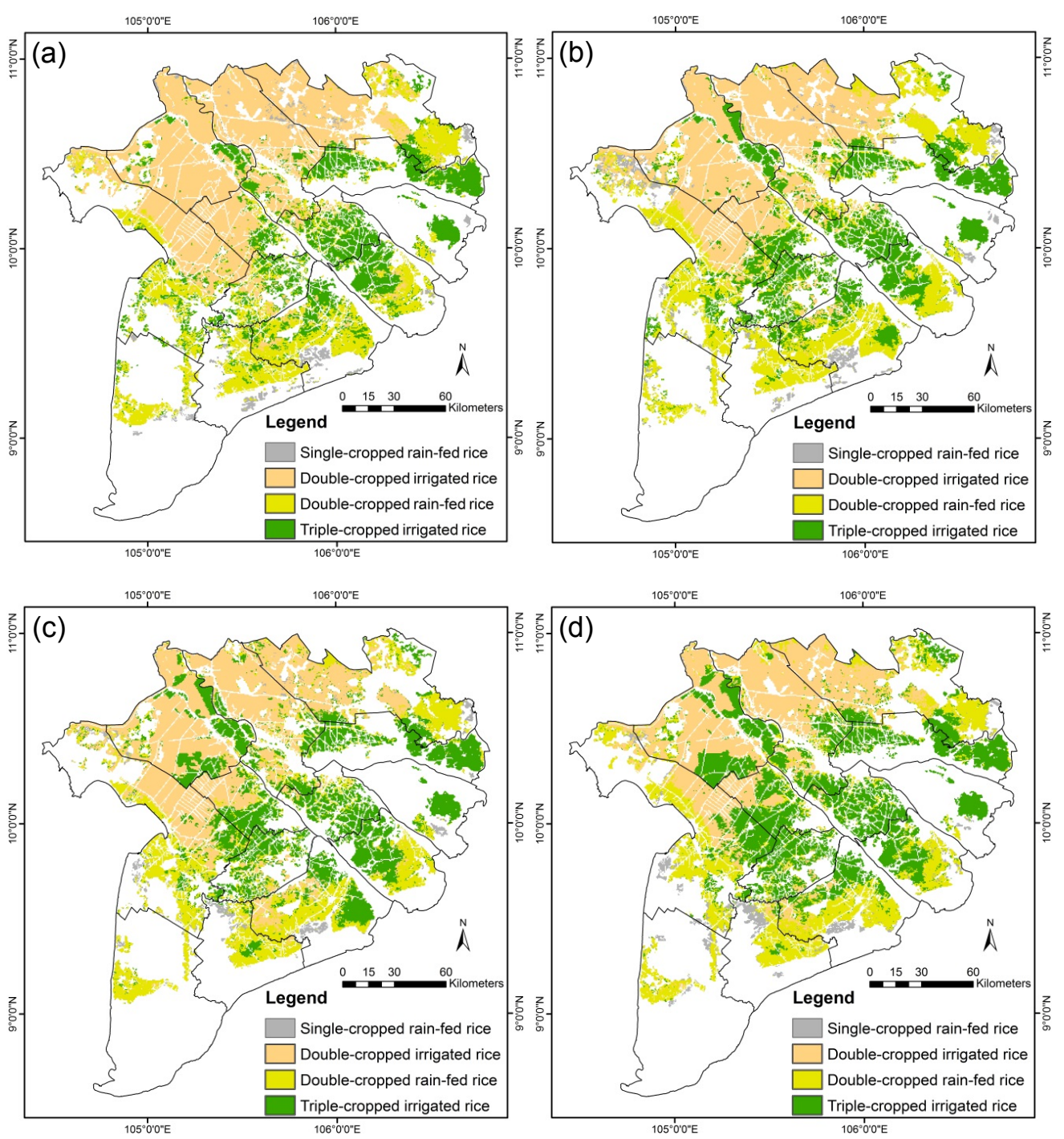
Figure 8. Cont.
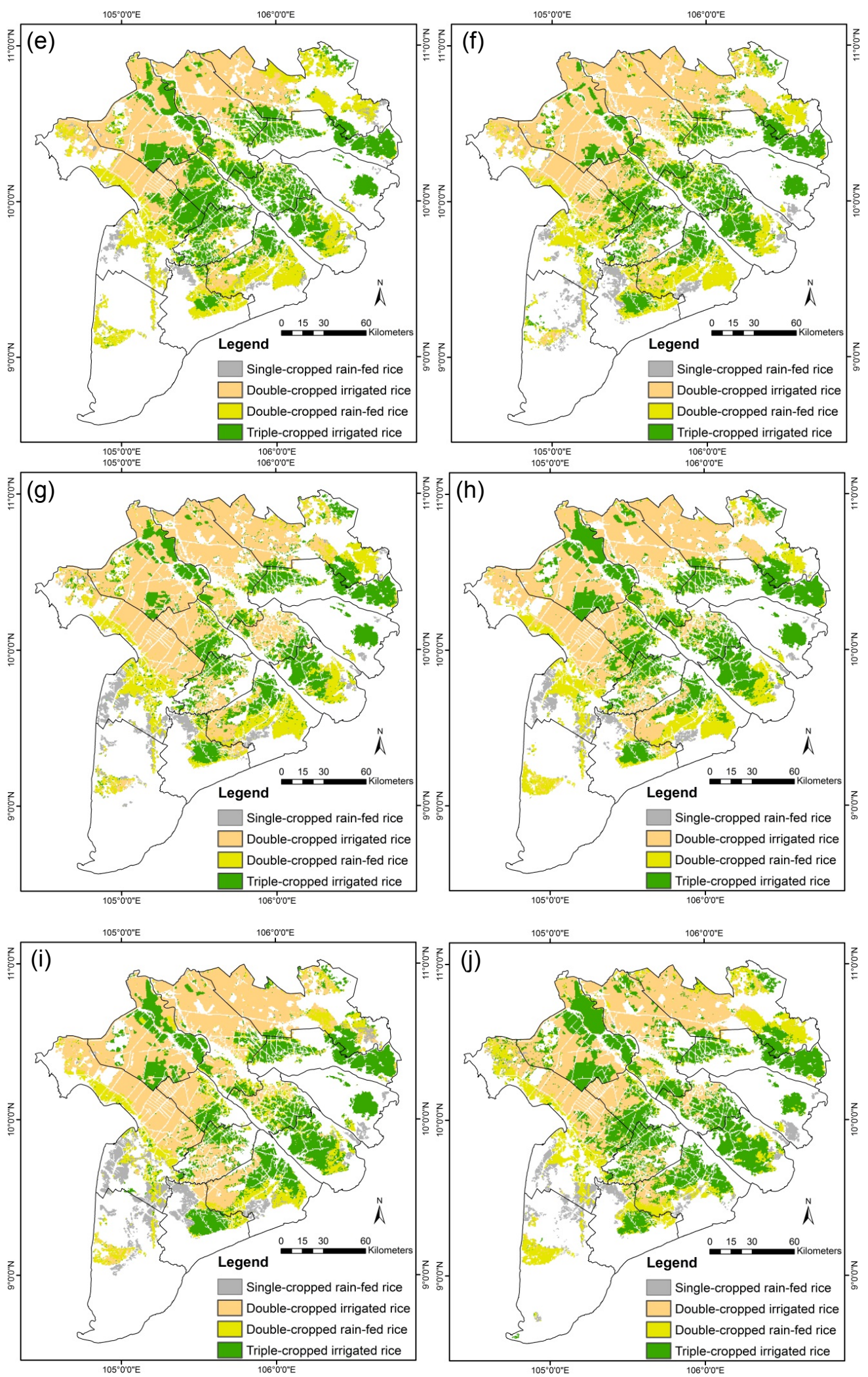
Figure 8. Cont.
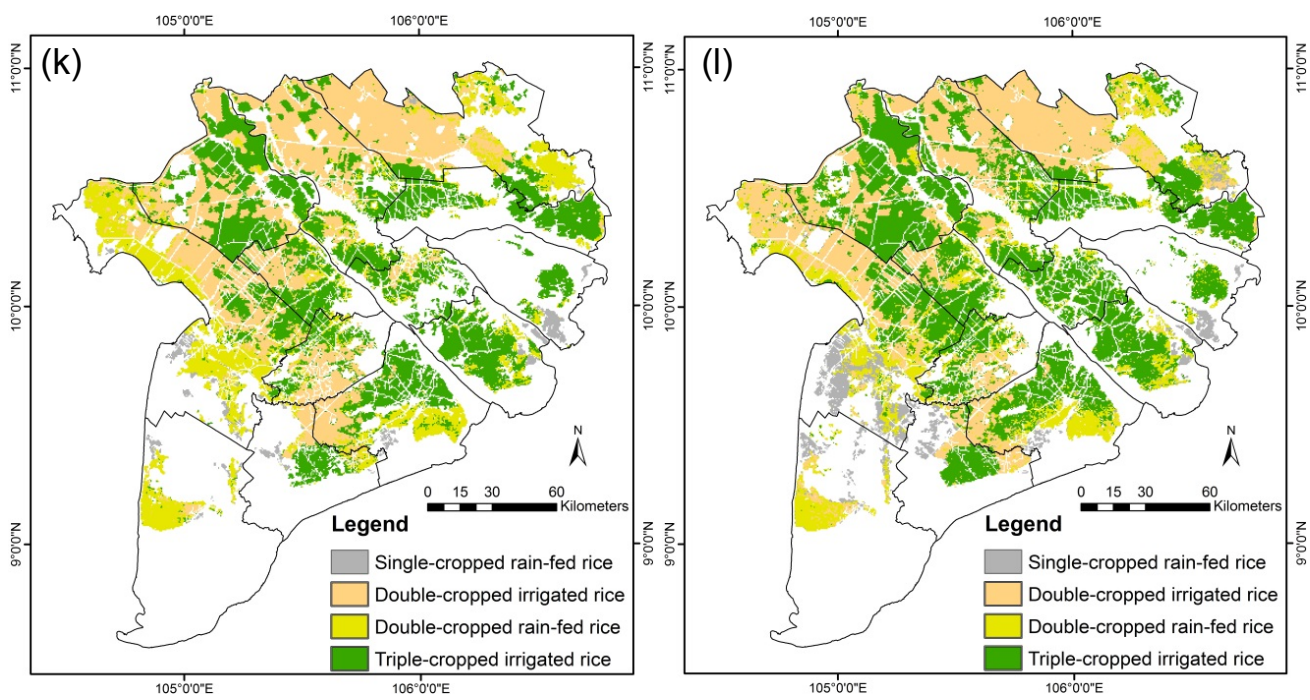

The yearly rice area data and the relative changes in the extent of rice-harvested area for each rice cropping system during the period 2001 to 2012 were investigated (Tables 3 and 4). The results indicated that the total area of rice cultivation had remarkably increased approximately $1,255 \mathrm{~km}^{2}$ from $19,047.5 \mathrm{~km}^{2}$ in 2001 to 20,302.5 ha in 2012 (Table 3). When investigating the change within each rice category, from 2001 to 2012 the largest change was observed for the triple-cropped irrigated rice, which had remarkably increased approximately $6,593.8 \mathrm{~km}^{2}(31.6 \%)$ (Table 4) from $2,722.8 \mathrm{~km}^{2}$ in 2001 to $9,316.5 \mathrm{~km}^{2}$ in 2012 (Table 4). However, the areas of double-cropped irrigated rice and double-cropped rain-fed rice systems had been reduced approximately $-19.2 \%$ and $-7.4 \%$, respectively. The area reduction of double-cropped irrigated rice was due to the conversion of this cropping system to the triple-cropped irrigated rice to increase total rice production per annum.

Table 3. Harvesting areas of rice cropping systems during 2001 to 2012.

\begin{tabular}{|c|c|c|c|c|c|c|c|c|c|c|c|c|c|}
\hline \multirow{2}{*}{ Year } & \multicolumn{3}{|c|}{$\begin{array}{c}\text { Single-Cropped } \\
\text { Rain-Fed Rice }\end{array}$} & \multicolumn{3}{|c|}{$\begin{array}{c}\text { Double-Cropped } \\
\text { Irrigated Rice } \\
\end{array}$} & \multicolumn{3}{|c|}{$\begin{array}{c}\text { Double-Cropped } \\
\text { Rain-Fed Rice } \\
\end{array}$} & \multicolumn{3}{|c|}{$\begin{array}{l}\text { Triple-Cropped } \\
\text { Irrigated Rice }\end{array}$} & \multirow{2}{*}{$\frac{\text { Total }}{\mathbf{k m}^{2}}$} \\
\hline & $\begin{array}{c}\text { Pixel } \\
\text { Count } \\
\end{array}$ & & $\%$ & $\begin{array}{c}\text { Pixel } \\
\text { Count } \\
\end{array}$ & $\mathbf{k m}^{2}$ & $\%$ & $\begin{array}{l}\text { Pixel } \\
\text { Count }\end{array}$ & $\mathrm{m}^{2}$ & $\%$ & $\begin{array}{c}\text { Pixel } \\
\text { Count } \\
\end{array}$ & $\mathbf{k m}^{2}$ & $\%$ & \\
\hline 00 & & 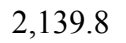 & 110 & & & & & & & & & & \\
\hline 200 & & 772 & 4.0 & & & & & & & & & & \\
\hline & & 498 & & & & & & & $2 t$ & & & & \\
\hline & & 65 & & & & & & & & & & & \\
\hline & & 6 & & & & 33 & & & 25.8 & & & & \\
\hline & & & & & & & & & & & & & \\
\hline & 17 & 108 & & & 8,8 & 46 & & & 20 & & & & \\
\hline & & & & & & & & & & & & & \\
\hline 200 & 6514 & 1,63 & & & 9,0 & 45 & & 3,1 & 15.7 & & 6,0 & 30.6 & $19,909.8$ \\
\hline 201 & 4,100 & $1,04 /$ & & & $6,875.8$ & 50.1 & 14,257 & $3,504.3$ & 18.7 & & & & $19,052.8$ \\
\hline 201 & 2,032 & 508.0 & 2. & 26,232 & $6,558.0$ & 34.7 & 16,522 & $4,130.5$ & 21.9 & 30,715 & $7,678.8$ & 40.7 & $18,875.3$ \\
\hline 2012 & 5,056 & $1,264.0$ & 0.2 & 25,861 & $6,465.3$ & 31.8 & 13,027 & $3,256.8$ & 16.0 & 37,266 & $9,316.5$ & 45.9 & $20,302.5$ \\
\hline
\end{tabular}


The reduction of double-cropped rain-fed rice area could also be partly explained by the conversion of this cropping system to the single-cropped rain-fed rice or single rice-based shrimp farming system along coastal areas, due to the high profit of shrimp culture. There was an increase $(8.8 \%)$ in the area of double-cropped irrigated rice between 2005 and 2006, mainly attributed to the decrease of the triple-cropped rice area $(-7.1 \%)$, because of environmental concerns. The intensive rice cultivation of three crops per year in diked areas had long interrupted the water flows, which brought sediments and soil nutrients from the two main rivers into rice fields, creating land degradation, water pollution and pest outbreaks that consequently lowered the rice crop yields. Thus, the local authorities opened sluices along these rivers, allowing the triple-cropped rice fields to be abandoned during the 2006 flood season (July-November). The area of triple-cropped rice had increased approximately 13.8\% between 2001 and 2002 and 9.1\% between 2009 and 2010, attributed to the decreased area of double-cropped irrigated rice of $-13.1 \%$ between 2001 and 2002 and $-9.4 \%$ between 2009 and 2010 , respectively. The increased area of triple-cropped rice cultivation during these two periods was indicated by changes in cropping practices, especially in the upper part of the region. In addition, more dykes were likely constructed by the local governments to protect rice fields from floods, allowing farmers inside these dykes to practice three rice crops per year.

Table 4. Changes in harvesting area derived from MODIS-based classification results for rice cropping systems for every year period during 2001-2012.

\begin{tabular}{ccccccccc}
\hline \multirow{2}{*}{ Period } & \multicolumn{2}{c}{$\begin{array}{c}\text { Single-Cropped } \\
\text { Rain-Fed Rice }\end{array}$} & \multicolumn{2}{c}{$\begin{array}{c}\text { Double-Cropped } \\
\text { Irrigated Rice }\end{array}$} & \multicolumn{2}{c}{$\begin{array}{c}\text { Double-Cropped } \\
\text { Rain-Fed Rice }\end{array}$} & \multicolumn{2}{c}{$\begin{array}{c}\text { Triple-Cropped } \\
\text { Irrigated Rice }\end{array}$} \\
\cline { 2 - 8 } & $\mathbf{k m}^{\mathbf{2}}$ & $\mathbf{\%}$ & $\mathbf{k m}^{\mathbf{2}}$ & $\mathbf{\%}$ & $\mathbf{k m}^{\mathbf{2}}$ & $\mathbf{\%}$ & $\mathbf{k m}^{\mathbf{2}}$ & $\mathbf{\%}$ \\
\hline $2001-2002$ & $-1,367.0$ & -7.2 & $-9,551$ & -13.1 & $1,324.0$ & 6.5 & $2,713.8$ & 13.8 \\
$2002-2003$ & -274.0 & -1.3 & $-1,042$ & 0.2 & -929.0 & -3.8 & 688.3 & 4.9 \\
$2003-2004$ & 158.8 & 0.8 & $-3,565$ & -5.7 & 271.3 & 0.7 & 955.0 & 4.2 \\
$2004-2005$ & -6.8 & 0.1 & -292 & 0.6 & -375.5 & -1.2 & -110.5 & 0.5 \\
$2005-2006$ & 340.8 & 1.7 & 7,579 & 8.8 & -491.5 & -3.4 & $-1,121.5$ & -7.1 \\
$2006-2007$ & 95.3 & 0.5 & 3,297 & 4.6 & -457.5 & -2.3 & -579.8 & -2.9 \\
$2007-2008$ & -289.5 & -1.5 & $-1,996$ & -2.6 & -378.3 & -2.0 & $1,149.3$ & 6.1 \\
$2008-2009$ & 838.8 & 4.0 & 2,919 & 1.6 & -305.5 & -2.4 & -323.8 & -3.2 \\
$2009-2010$ & -589.0 & -2.7 & $-8,709$ & -9.4 & 437.0 & 3.0 & $1,472.3$ & 9.1 \\
$2010-2011$ & -539.0 & -2.8 & $-1,271$ & -1.3 & 566.3 & 3.2 & 113.0 & 1.0 \\
$2011-2012$ & 756.0 & 3.5 & -371 & -2.9 & -873.8 & -5.8 & $1,637.8$ & 5.2 \\
$2001-2012$ & -875.8 & -5.0 & $-3,250.5$ & -19.2 & $-1,212.5$ & -7.4 & $6,593.8$ & 31.6 \\
\hline
\end{tabular}

\section{Conclusions}

This study aimed to develop a phenology-based classification approach for a decadal assessment of rice cropping systems in the Mekong Delta (South Vietnam) from the MODIS EVI time-series data using EMD. Although several error sources, such as cloud cover, mixed-pixel issues and resolution bias, between the classified maps and the ground reference data contributed to the lowered accuracy level of classification results, the overall accuracies and Kappa coefficients achieved by comparisons between the classified maps and the ground reference data were generally higher than $80 \%$ and 0.7 , respectively. These results were reaffirmed by close correlation between the MODIS-derived rice area 
and the government rice area statistics at the provincial level $\left(\mathrm{R}^{2}>0.8\right)$, in all cases. The MODIS-derived rice area was, however, slightly overestimated, with an REA ranging between 0.9 and $12 \%$, due to mixed-pixel issues and discrepancies when using the number of crops as multipliers for estimating the rice-harvested areas. An examination of changes in rice cropping practices indicated that the area of triple-cropped rice had increased approximately $6,593.8 \mathrm{~km}^{2}$ (31.6\%) during 2001 to 2012, while the values for single-cropped rain-fed rice, double-cropped irrigated rice and double-cropped rain-fed rice were $-5.0 \%,-19.2 \%$ and $-7.4 \%$, respectively. Ultimately, our findings from this study confirmed the effectiveness and validity of the methods for automatically delineating rice-cropping systems in the region. Such a phenology-based classification approach could annually provide quantitative information of rice growing areas, with the REA less than $16 \%$, and is, thus, proposed for rice crop monitoring in the region and elsewhere around the globe.

\section{Acknowledgments}

This study is financed by the Taiwan National Science Council (NSC102-2923-E-008-001-MY3) and the Southeast Asian Regional Center for Graduate Study and Research in Agriculture (GCS13-4204). The financial support is fully acknowledged. The field data and rice statistics were collected with the help of the staff from the Faculty of Agriculture and Natural Resources, An Giang University, Vietnam.

\section{Conflicts of Interest}

The authors declare no conflict of interest.

\section{References}

1. Global Climate Changes and Rice Food Security. Available online: http://www.hechoenperu.org.pe/ fao/docs/Agriculture/3-Nguyen.pdf (accessed on 16 May 2013).

2. Timmer, C.P. A World without Agriculture: The Structural Transformation in Historical Perspective; American Enterprise Institute: Washington, DC, USA, 2009.

3. Evenson, R.E.; Gollin, D. Crop Varietal Improvement and Its Effects on Productivity: The Impact of International Agricultural Research; CABI Publishing: Wallingford, UK, 2003.

4. Metz, B.; Davidson, O.R.; Bosch, P.R.; Dave, R.; Meyer, L.A. Contribution of Working Groups I, II and III to the Fourth Assessement Report of the Intergovernmental Panel on Climate Change; Cambridge University Press: Cambridge, UK and New York, NY, USA, 2007.

5. Furuya, J.; Kobayashi, S. Impact of Global Warming on Agricultural Product Markets: Stochastic World Food Model Analysis. In Adaptation and Mitigation Strategies for Climate Change; Sumi, A., Fukushi, K., Hiramatsu, A., Eds.; Springer Japan: Tokyo, Japan, 2009; pp. 19-35.

6. Matthews, R.; Wassmann, R. Modelling the impacts of climate change and methane emission reductions on rice production: A review. Eur. J. Agron. 2003, 19, 573-598.

7. Matthews, R.B.; Kropff, M.J.; Bachelet, D. Modeling the Impact of Climate Change on Rice Production in Asia; CAB International in association with the International Rice Research Institute: Wallingford, UK, 1995. 
8. Matthews, R.B.; Kropff, M.J.; Horie, T.; Bachelet, D. Simulating the impact of climate change on rice production in Asia and evaluating options for adaptation. Agric. Syst. 1997, 54, 399-425.

9. Peng, S.; Huang, J.; Sheehy, J.E.; Laza, R.C.; Visperas, R.M.; Zhong, X.; Centeno, G.S.; Khush, G.S.; Cassman, K.G. Rice yields decline with higher night temperature from global warming. Proc. Natl. Acad. Sci. U.S.A. 2004, 101, 9971-9975.

10. Van Duivenbooden, N.; Abdoussalam, S.; Ben Mohamed, A. Impact of climate change on agricultural production in the sahel-Part 2. Case study for groundnut and cowpea in Niger. Clim. Chang. 2002, 54, 349-368.

11. Chipanshi, A.C.; Chanda, R.; Totolo, O. Vulnerability assessment of the maize and sorghum crops to climate change in botswana. Clim. Chang. 2003, 61, 339-360.

12. Ericson, J.P.; Vörösmarty, C.J.; Dingman, S.L.; Ward, L.G.; Meybeck, M. Effective sea-level rise and deltas: Causes of change and human dimension implications. Glob. Planet. Chang. 2006, 50, 63-82.

13. OECD-FAO Agricultural Outlook 2006-2015. Available online: http://www.euroqualityfiles.net/ Documents\%20EUAM\%20and\%20CEECAP/Europe/Future\%20policy/37038911.pdf (accessed on 16 September 2013).

14. Godfray, H.C.J.; Beddington, J.R.; Crute, I.R.; Haddad, L.; Lawrence, D.; Muir, J.F.; Pretty, J.; Robinson, S.; Thomas, S.M.; Toulmin, C. Food security: The challenge of feeding 9 billion people. Science 2010, 327, 812-818.

15. GSO, Statistical Yearbook of Vietnam. Available online: http://www.gso.gov.vn (accessed on 10 November 2013).

16. Nguyen, V.N.; Do, M.H.; Nguyen, N.A.; Le, V.K. Rice Production in the Mekong Delta (Vietnam): Trends of Development and Diversification. In Proceedings of the Mekong Rice Conference 2004: Rice the Environment, and Livelihoods for the Poor, Ho Chi Minh City, Vietnam, 15-17 October 2004.

17. Xiao, X.; Boles, S.; Frolking, S.; Li, C.; Babu, J.Y.; Salas, W.; Moore, B., III. Mapping paddy rice agriculture in South and Southeast Asia using multi-temporal modis images. Remote Sens. Environ. 2006, 100, 95-113.

18. Xiao, X.; Boles, S.; Liu, J.; Zhuang, D.; Frolking, S.; Li, C.; Salas, W.; Moore, B., III. Mapping paddy rice agriculture in southern China using multi-temporal MODIS images. Remote Sens. Environ. 2005, 95, 480-492.

19. Chen, C.F.; Son, N.T.; Chang, L.Y.; Chen, C.R. Classification of rice cropping systems by empirical mode decomposition and linear mixture model for time-series modis $250 \mathrm{~m}$ NDVI data in the Mekong Delta, Vietnam. Int. J. Remote Sens. 2011, 32, 5115-5134.

20. Chen, C.F.; Son, N.T.; Chen, C.R.; Chang, L.Y. Wavelet filtering of time-series moderate resolution imaging spectroradiometer data for rice crop mapping using support vector machines and maximum likelihood classifier. J. Appl. Remote Sens. 2011, 5, doi:10.1117/1.3595272.

21. Pittman, K.; Hansen, M.C.; Becker-Reshef, I.; Potapov, P.V.; Justice, C.O. Estimating global cropland extent with multi-year modis data. Remote Sens. 2010, 2, 1844-1863.

22. Zhang, M.; Zhou, Q.; Chen, Z.; Liu, J.; Zhou, Y.; Cai, C. Crop discrimination in Northern China with double cropping systems using fourier analysis of time-series MODIS data. Int. J. Appl. Earth Obs. Geoinf. 2008, 10, 476-485. 
23. Canisius, F.; Turral, H.; Molden, D. Fourier analysis of historical NOAA time series data to estimate bimodal agriculture. Int. J. Remote Sens. 2007, 28, 5503-5522.

24. Atkinson, P.M.; Jeganathan, C.; Dash, J.; Atzberger, C. Inter-comparison of four models for smoothing satellite sensor time-series data to estimate vegetation phenology. Remote Sens. Environ. 2012, 123, 400-417.

25. Chen, C.-F.; Huang, S.-W.; Son, N.-T.; Chang, L.-Y. Mapping double-cropped irrigated rice fields in Taiwan using time-series satellite pour I'observation de la terre data. J. Appl. Remote Sens. 2011, 5, doi:10.1117/1.3595276.

26. Galford, G.L.; Mustard, J.F.; Melillo, J.; Gendrin, A.; Cerri, C.C.; Cerri, C.E.P. Wavelet analysis of MODIS time series to detect expansion and intensification of row-crop agriculture in Brazil. Remote Sens. Environ. 2008, 112, 576-587.

27. Huang, N.E.; Shen, Z.; Long, S.R.; Wu, M.C.; Shih, H.H.; Zheng, Q.; Yen, N.-C.; Tung, C.C.; Liu, H.H. The empirical mode decomposition and the hilbert spectrum for nonlinear and non-stationary time series analysis. Proc. R. Soc. Lond. A 1998, 454, 903-995.

28. Huang, N.E.; Shen, S.S.P. Hilbert-Huang Transform and Its Applications; World Scientific Publishing Co. Pte. Ltd.: Singapore, 2005.

29. Gumma, M.K.; Nelson, A.; Thenkabail, P.S.; Singh, A.N. Mapping rice areas of south asia using MODIS multitemporal data. J. Appl. Remote Sens. 2011, 5, doi:10.1117/1.3619838.

30. Bridhikitti, A.; Overcamp, T.J. Estimation of Southeast Asian rice paddy areas with different ecosystems from moderate-resolution satellite imagery. Agric. Ecosyst. Environ. 2012, 146, 113-120.

31. Bolstad, P.V.; Lillesand, T.M. Rapid maximum likelihood classification. Photogramm. Eng. Remote Sens. 1991, 57, 67-74.

32. A Training Algorithm for Optimal Margin Classiers. Available online: http://citeseerx.ist.psu.edu/ viewdoc/download?doi=10.1.1.103.1189\&rep=rep1\&type=pdf (accessed on 16 March 2013).

33. Benediktsson, J.A.; Swain, P.H.; Ersoy, O.K. Neural network approaches versus statistical methods in classification of multisource remote sensing data. IEEE Trans. Geosci. Remote Sens. 1989, 28, 540-552.

34. Deng, F.; Su, G.; Liu, C. Seasonal variation of MODIS vegetation indexes and their statistical relationship with climate over the subtropic evergreen forest in Zhejiang, China. IEEE Geosci. Remote Sens. Lett. 2007, 4, 236-240.

35. Wang, Q.; Adiku, S.; Tenhunen, J.; Granier, A. On the relationship of NDVI with leaf area index in a deciduous forest site. Remote Sens. Environ. 2005, 94, 244-255.

36. Stroppiana, D.; Boschetti, M.; Brivio, P.A.; Nizzetto, L.; di Guardo, A. Forest leaf area index in an alpine valley from medium resolution satellite imagery and in situ data. J. Appl. Remote Sens. 2012, 6, doi:10.1117/1.JRS.6.063528.

37. Viña, A.; Gitelson, A.A.; Nguy-Robertson, A.L.; Peng, Y. Comparison of different vegetation indices for the remote assessment of green leaf area index of crops. Remote Sens. Environ. 2011, $115,3468-3478$.

38. Boschetti, M.; Stroppiana, D.; Brivio, P.A.; Bocchi, S. Multi-year monitoring of rice crop phenology through time series analysis of MODIS images. Int. J. Remote Sens. 2009, 30, 4643-4662.

39. Zhang, X.; Friedl, M.A.; Schaaf, C.B.; Strahler, A.H.; Hodges, J.C.F.; Gao, F.; Reed, B.C.; Huete, A. Monitoring vegetation phenology using MODIS. Remote Sens. Environ. 2003, 84, 471-475. 
40. Vina, A.; Gitelson, A.A.; Rundquist, D.C.; Keydan, G.; Leavitt, B.; Schepers, J. Monitoring maize (Zea mays L.) phenology with remote sensing. Agron. J. 2004, 96, 1139-1147.

41. MODIS Land Surface Reflectance. Available online: http://modis-sr.ltdri.org. (accessed on 16 February 2012).

42. Wardlow, B.D.; Egbert, S.L.; Kastens, J.H. Analysis of time-series MODIS $250 \mathrm{~m}$ vegetation index data for crop classification in the U.S. Central Great Plains. Remote Sens. Environ. 2007, 108, 290-310.

43. Thenkabail, P.S.; Schull, M.; Turral, H. Ganges and indus river basin land use/land cover (LULC) and irrigated area mapping using continuous streams of MODIS data. Remote Sens. Environ. 2005, 95, 317-341.

44. Son, N.T.; Chen, C.F.; Chen, C.R.; Chang, L.Y. Satellite-based investigation of flood-affected rice cultivation areas in Chao Phraya River Delta, Thailand. ISPRS J. Photogramm. Remote Sens. 2013, 86, 77-88.

45. Chen, C.F.; Chen, C.R.; Son, N.T. Investigating rice cropping practices and growing areas from MODIS data using empirical mode decomposition and support vector machines. GISci. Remote Sens. 2012, 49, 117-138.

46. Salas, S.L.; Hille, E.; Etgen, G.J. Calculus: One and Several Variables, 10th ed.; Wiley: Hoboken, NJ, USA, 2007.

(C) 2013 by the authors; licensee MDPI, Basel, Switzerland. This article is an open access article distributed under the terms and conditions of the Creative Commons Attribution license (http://creativecommons.org/licenses/by/3.0/). 